\title{
GESTÃO DE PESSOAS: UMA ABORDAGEM ESTRATÉGICA DA ADMINISTRAÇÃO DE RECURSOS HUMANOS, SUA IMPORTÂNCIA E PAPEL EFETIVAMENTE DESEMPENHADO NAS ORGANIZAÇÕES CONTEMPORÂNEAS
}

\author{
Ayslan Cavalcante Peloso', Hiroshi Wilson Yonemoto² \\ ${ }^{1}$ Discente do curso de Administração das Faculdades Integradas "Antônio Eufrásio de Toledo" de Presidente Prudente. Bolsista do \\ Programa de Iniciação Científica "Gestão e Sustentabilidade". ${ }^{2}$ Docente do curso de Administração das Faculdades Integradas "Antônio \\ Eufrásio de Toledo" de Presidente Prudente. E-mail: ayslanpeloso@bol.com.br
}

\section{RESUMO}

O presente trabalho teve por objetivo analisar a importância da Administração Estratégica de Recursos Humanos dentro das organizações empresariais contemporâneas. Ao abordar a área de Gestão de Pessoas das empresas, o trabalho teve de se aprofundar nas relações entre Administração de Recursos Humanos e estratégia empresarial, a fim de mostrar qual o entrelaçamento entre esses dois conceitos tão importantes da realidade das instituições. Também foi objetivo dessa obra conceituar o que é Gestão de Pessoas e quais as suas atribuições. Além disso, foi possível descrever, por meio de um breve histórico, o desenvolvimento da área de Gestão de Pessoas no Brasil, desde os primórdios, até os dias atuais. Após isso o artigo procurou abordar a importância da Administração de Recursos Humanos na gestão estratégica das organizações, mostrando que a área de Gestão de Pessoas deve estar atrelada aos objetivos estratégicos da organização. Posteriormente, foi possível descrever o papel efetivamente desempenhado pela Administração de Recursos Humanos no dia-a-dia das empresas, bem como suas contribuições para a valorização dos trabalhos, para o envolvimento dos colaboradores, e para o crescimento e desenvolvimento da empresa como um todo. Foi possível também mensurar as atividades de Gestão de Pessoas e identificar os resultados decorrentes de uma Administração de Recursos Humanos eficiente e eficaz. Ao final, é possível enxergar a extrema importância dessa área para a organização, já que ela traz inúmeros retornos e possibilita à empresa ter um diferencial competitivo.

Palavras-chave: Gestão de Pessoas. Administração de Recursos Humanos. Empresas. Mensuração. Resultados.

PEOPLE MANAGEMENT: A STRATEGIC APPROACH OF HUMAN RESOURCES MANAGEMENT, ITS IMPORTANCE AND ROLE EFFECTIVELY PLAYED IN CONTEMPORARY ORGANIZATIONS

\begin{abstract}
This study aimed to analyze the importance of the Strategic Management of Human Resources within the contemporary business organizations. In addressing the area of People Management of companies, the work was to deepen the relationship between Human Resource Management and business strategy in order to show that the intertwining of these two concepts as important institutions of reality. Another objective was to conceptualize what People Management is and its assignments. Furthermore, it was possible to describe, through a brief history of the development of the area of People Management in Brazil, from the earliest times to the present day. After that the article sought to address the importance of Human Resource Management in the strategic management of organizations, showing that the area of Personnel Management should be tied to the organization's strategic goals. Later, it was possible to effectively describe the role played by the Human Resources Administration in day-to-day business as well as their contributions to the appreciation of the work, for employee involvement, and growth and development of the company as a whole. It was also possible to measure the activity of Personnel Management and identify the results arising from the Human Resources Administration efficient and effective. At the end, it is possible to see the extreme importance of this area for the organization, as it brings many returns and enables the company to have a competitive edge.
\end{abstract}

Key Words: People Management. Human Resource Management. Companies. Measurement. Results.

] 


\section{INTRODUÇÃO}

Abordar a Administração de Recursos Humanos nas corporações é de grande relevância se observado que as empresas têm dado cada vez mais importância às suas áreas de Gestão de Pessoas, procurando fazer dos colaboradores seus recursos mais importantes no desempenho dos negócios. Isso mostra que a Administração de Recursos Humanos está em plena expansão.

Isso é decorrente de uma nova visão que as empresas têm das pessoas que fazem parte de seu quadro de funcionários. Elas passaram de meros empregados, que apenas executavam seu serviço, para colaboradores, que além de suas atividades são capazes de contribuir para a empresa com o seu pensamento, pensamento esse estratégico, que enxerga problemas e propõe soluções eficientes e eficazes o bastante para agregar valor a companhia e gerar um diferencial competitivo dentro da organização.

Diante disso, o presente artigo visa verificar a importância da área de Gestão de Pessoas na realidade das empresas, analisar o seu papel efetivamente desempenhado no mundo dos negócios e também abordar a mensuração da Administração de Recursos Humanos nas corporações.

Os investimentos em recursos humanos estão cada vez maiores. São várias as empresas que criam e implementam programas para 0 desenvolvimento dos seus profissionais. Ao fazer isso, as empresas não estão investindo apenas nos colaboradores, mas sim no próprio negócio, já que as pessoas que trabalham na empresa fazem parte da organização, e ao investir nelas, a empresa está investindo no seu próprio negócio.

É claro que tais investimentos e os resultados obtidos devem ser adequadamente geridos e mensurados, para verificar-se o real retorno dos trabalhos feitos em Gestão de
Pessoas. Se não houver a devida mensuração não será possível saber se os retornos obtidos estão em adequação ao anteriormente estabelecido.

Se tantas organizações têm investido na Administração de Recursos Humanos com foco estratégico, é porque isso traz resultados efetivos, pois senão, os recursos seriam alocados em outras áreas da organização.

Diante desse cenário, $\circ$ presente trabalho, por intermédio de pesquisas bibliográficas, procurou desvendar quais são as vantagens de se investir na Administração de Recursos Humanos com foco estratégico.

Observou-se então que tais investimentos trazem retornos efetivos para a empresa, principalmente o envolvimento dos colaboradores com a empresa e com os trabalhos desempenhados, além do aumento da produtividade dos trabalhadores e da rentabilidade por eles gerada, o que acarreta um importante diferencial competitivo da empresa diante do atual acirrado mercado mundial.

Pesquisar essa nova visão da área de Gestão de Pessoas na realidade das empresas é a problemática do presente artigo científico, que traz resultados e considerações finais a respeito do tema abordado.

\section{METODOLOGIA}

Para sua confecção, o artigo, como todo trabalho científico, segue uma metodologia, que é um modelo de realização de tarefas.

Para Barros e Lehfeld (2007, p. 1-2) a metodologia pode ser assim definida:
A metodologia é entendida como uma disciplina que se relaciona com a epistemologia. Consiste em estudar e avaliar os vários métodos disponíveis, identificando suas limitações ou não no que diz respeito às implicações de suas utilizações. 
A metodologia, quando aplicada, examina e avalia os métodos e as técnicas de pesquisa, bem como a geração ou verificação de novos métodos que conduzam à captação e ao processamento de informações com vistas à resolução de problemas de investigação.

No trabalho foram usadas pesquisas bibliográficas como fontes.

De acordo com Cervo e Bervian (1983, p.

55) a pesquisa bibliográfica pode ser caracterizada da seguinte forma:

A pesquisa bibliográfica procura explicar um problema a partir de referências teóricas publicadas em documentos. Pode ser realizada independentemente ou como parte da pesquisa descritiva ou experimental. Em ambos os casos, busca conhecer e analisar as contribuições culturais ou científicas do passado existentes sobre um determinado assunto, tema ou problema.

Em conjunto com as pesquisas bibliográficas 0 presente trabalho científico utilizou-se do método dedutivo. Cruz e Ribeiro (2003, p. 34) afirmam que "para a dedução se utiliza a síntese. Através de um fato geral e conhecido, podemos dividi-lo e conhecer as suas partes."

Esta é, portanto, a metodologia utilizada para a elaboração deste artigo.

\section{RESULTADOS}

Observa-se que 0 que conhecemos atualmente como Gestão de Pessoas só é o que vimos atualmente depois de passar por um considerável processo de transformação e evolução.

Verifica-se que a Administração de Recursos Humanos é uma área que está em expansão no âmbito empresarial dos dias atuais. Além disso, é um setor de grande importância para a empresa, pois é o responsável por gerir as pessoas, que constituem o capital humano de uma corporação, desempenhando um papel fundamental para a corporação.

Além de ser importante, a Gestão de Pessoas quando realizada de forma eficiente e eficaz, alinhada aos objetivos estratégicos da empresa, tende a gerar resultados positivos para a organização em diversos aspectos, como financeiro, pesquisa e desenvolvimento, inovação, motivacional, entre outros.

É importante observar também que além de se investir em Gestão de Pessoas sejam utilizadas ferramentas para a mensuração dos resultados obtidos.

Logo, investir, gerenciar e controlar a área de Gestão de Pessoas são atividades que quando bem executadas podem proporcionar um diferencial competitivo para a empresa a fim de que esta se diferencie diante das suas concorrentes e se destaque no acirrado mundo dos negócios.

\section{O CONCEITO DE GESTÃO DE PESSOAS}

Atualmente, muito se ouve falar sobre Gestão de Pessoas, ou Administração de Recursos Humanos, termos diferentes, mas que são utilizados com a mesma finalidade e que estão cada vez mais frequentes no dia-a-dia das organizações e de seus gestores. Além destes termos, outros ainda são utilizados com o mesmo intuito, como descrito por Chiavenato (2004, p. 2) no trecho a seguir:

[...] uma das áreas empresariais que mais sofre mudanças é a área de recursos humanos $(\mathrm{RH})$. As mudanças são tantas e tamanhas que até o nome da área está mudando. Em muitas organizações, a denominação administração de recursos Humanos $(\mathrm{ARH})$ está sendo substituída por termos como gestão de talentos humanos, gestão de parceiros ou de colaboradores, gestão do capital 
humano, administração do capital intelectual e até Gestão de Pessoas ou Gestão com Pessoas. Diferentes nomes para representar um novo espaço e configuração da área.

Apesar de diferentes, os termos utilizados possuem mesma essência. Diante disso, faz-se necessário saber qual é o real conceito dessas terminologias, a fim de que se torne possível o entendimento do objeto de atuação da área em questão.

Segundo Chiavenato (2004, p. 6) o que chamamos de Gestão de Pessoas pode ser conceituado da seguinte forma:
A Gestão de Pessoas é uma área muito sensível à mentalidade que predomina nas organizações. Ela é contingencial e situacional, pois depende de vários aspectos, como a cultura que existe em cada organização, da estrutura organizacional adotada, das características do contexto ambiental, do negócio da organização, da tecnologia utilizada, dos processos internos e de uma infinidade de outras variáveis importantes.

Após tal conceituação, observa-se a complexidade e também a subjetividade do que é Gestão de Pessoas. Por ser abrangente, é objeto de estudo e pesquisa de muitos autores e gestores, a fim de buscar o aprimoramento e desenvolvimento de tal área no âmbito organizacional.

Ainda nessa linha de raciocínio, Sovienski e Stigar (2008, p. 54) discorrem de forma bastante concisa sobre o tema Gestão de Pessoas no trecho a seguir:

A Gestão de Pessoas é caracterizada pela participação, capacitação, envolvimento e desenvolvimento do bem mais precioso de uma organização, o Capital Humano, que nada mais é do que as pessoas que a compõe. Cabe à área de Gestão de Pessoas a nobre função de humanizar as empresas. Apesar da Gestão de Pessoas ser um assunto tão atual na área de Administração, ainda é um discurso para muitas organizações, ou pelo menos não se tornou uma ação prática. Compete ao Departamento de Recursos Humanos promover, planejar, coordenar e controlar as atividades desenvolvidas relacionadas à seleção, orientação, avaliação de desempenho funcional $e$ comportamental, capacitação, qualificação, acompanhamento do pessoal da instituição num todo, assim como as atividades relativas à preservação da saúde e da segurança no ambiente de trabalho da Instituição.

Ainda no que tange à descrição do que é a Administração de Recursos Humanos, Fidelis e Banov (2006, p. 17) propõem de forma objetiva a função dessa área no contexto organizacional:
A administração de Recursos Humanos é uma área focada às políticas e práticas empresariais para administrar as pessoas em seu ambiente de trabalho. Por ser multidisciplinar, ela congrega a Sociologia Organizacional, a Psicologia do Trabalho, o Direito Trabalhista, a Medicina do Trabalho, a Engenharia do Trabalho, o Serviço Social, etc.

Como visto acima, é possível observar a abrangência da área de Gestão de Pessoas na organização e as vertentes pelas quais ela atua.

As pessoas dependem do trabalho como meio de subsistência, e por outro lado, as organizações precisam das pessoas para o desenvolvimento de suas atividades. Ora, isso significa que um depende do outro e o outro depende do um. E é diante desses fatores, que a Gestão de Pessoas vem para cuidar das relações entre pessoas e empresa. 
UM BREVE HISTÓRICO SOBRE A GESTÃO DE PESSOAS NO BRASIL

É importante ressaltar que a Administração de Recursos Humanos tal qual conhecemos hoje surgiu de forma muito mais primitiva do que aquela vista nos dias atuais, e desde seu surgimento essa área tem evoluído constantemente.

No que tange ao surgimento da área de Gestão de Pessoas, Marras (2000, p. 21) afirma que "tudo começou com a necessidade de 'contabilizar' os registros dos trabalhadores, com ênfase, obviamente, nas horas trabalhadas, faltas e atrasos para efeitos de pagamento ou de desconto. Tal qual se faz hoje". Ou seja, o profissional que atuava na Administração de Recursos Humanos era responsável apenas por verificar a freqüência dos trabalhadores, suas faltas e atrasos, para efeitos de pagamento dos empregados.

Nessa época então, o profissional responsável pela Administração de Recursos Humanos era visto de forma bem característica pelos operários, como afirma mais uma vez Marras (2000, p. 21) no trecho a seguir:

O 'capo del personale'; 'personnel chief' ou 'chefe de pessoal' do início do século XIX tinha em comum, tanto na Itália quanto nos Estados Unidos e no Brasil, as mesmas características que o definiram por muitos anos: um sujeito inflexível, seguidor das leis e dono de uma frieza incalculável na hora de demitir alguém. Dessa forma, ser enviado ao departamento pessoal foi por muitos anos sinônimo de estar sendo chamado para receber o bilhete azul. Por muitos anos os funcionários tiveram esse sentimento, e, talvez, em muitas empresas ainda hoje persista. No Brasil, com certeza.

Verificando-se a trajetória do desenvolvimento da Gestão de Pessoas, podemos analisar seu desenvolvimento histórico no Brasil dividindo-o em cinco fases evolutivas, desde os primórdios da atividade até os dias atuais.

A primeira fase da Administração de Recursos Humanos brasileira é descrita por Fidelis e Banov (2006, p. 21) quando os autores afirmam que ela existiu "antes de 1930, conhecida como fase contábil. Não havia legislação que disciplinasse o capital x trabalho". Além disso, Marras (2000, p. 26) também discorre sobre esta fase no trecho a seguir:
A fase contábil, pioneira da 'gestão de pessoal', também chamada de pré-histórica' por alguns autores, caracterizava-se pela preocupação existente com os custos da organização. Os trabalhadores eram vistos exclusivamente sob o enfoque contábil: comparava-se a mão- de-obra e, portanto, as entradas e saídas provenientes dessa conta deveriam ser registradas contabilmente.

Logo, verifica-se que nos primórdios, a Gestão de Pessoas era feita de forma extremamente metódica, com enfoque contábil, além de os trabalhadores serem vistos simploriamente como mão-de-obra das organizações.

Após a fase contábil, o advento da legislação trabalhista nacional proporcionou o surgimento de uma nova fase da Gestão de Pessoas. Para Fidelis e Banov (2006, p. 22) essa fase é caracterizada a seguir:

[...]de 1930 a 1950, conhecida
como fase legal. Surge a
preocupação com o aspecto
legal. Getúlio Vargas assumiu o
poder e criou o Ministério do
Trabalho, Indústria e Comércio
e o Departamento Nacional de
Trabalho. Em 1943, surge a
CLT e a reformulação da
Carteira Profissional.

Além disso, a fase legal foi marcada por mudanças significativas na área de Gestão de Pessoas, como reforça Marras (2000, p. 26) no 
trecho em que o autor afirma que "a fase legal registrou o aparecimento da função de chefe de pessoal, profissional cuja preocupação estava centrada no acompanhamento e na manutenção das recém-criadas leis trabalhistas da era getulista". Ou seja, o governo de Getúlio Vargas forçou um desenvolvimento e aprimoramento da área de Gestão de Pessoas, a qual viu-se obrigada a realizar suas atividades com maior zelo e profissionalismo, atendendo às exigências legais.

Pode-se dizer que foi a partir dessa fase que a área de Gestão de Pessoas ficou conhecida como uma área extremamente ligada à legislação, sobretudo a Trabalhista. Além disso, para muitos, Gestão de Pessoas é apenas atender à legislação vigente, fazendo isso de forma metódica. Nesse contexto, Fidelis e Banov (2006, p. 22) afirmam ainda sobre a fase legal da Administração de Recursos Humanos que este "é um período marcado pelo início da gestão burocrática e legalista de pessoas. Infelizmente, até hoje, para algumas empresas, Gestão de Pessoas significa atender às exigências da lei".

É claro que se foi o tempo em que Gestão de Pessoas era somente atender ás obrigações legais enquanto empresa. Observando-se 0 cenário atual das organizações fica nítido que isso mudou muito com o passar do tempo.

O desenvolvimento do setor industrial no Brasil acarretou uma nova fase na Gestão de Pessoas. Isso ocorreu pois o país teve que se adaptar para receber as empresas multinacionais, e realizar a Administração de Recursos Humanos de forma a atender os moldes internacionais então vigentes. Nessa época surge uma nova fase da Gestão de Pessoas, a qual Fidelis e Banov (2006, p. 22) afirmam que ocorreu "de 1950 a 1965, conhecida como fase tecnicista. Com a entrada das multinacionais no País e, com muita força, as indústrias automobilísticas iniciam a implantação do modelo americano de Gestão de Pessoas". Também sobre essa fase da Administração de Recursos Humanos, Marras (2000, p. 26) ainda afirma que:

A fase tecnicista foi a que
implantou no Brasil o modelo
americano de gestão de pessoal
e alavancou a função de RH ao
status orgânico de gerência. Foi
nessa oportunidade que o
presidente Juscelino Kubitschek
implementou a indústria
automobilística no nosso país,
momento em que os
empresários tiveram que aceitar
em seus organogramas a figura
do GRI. Obviamente algumas
modificações tiveram de ser
realizadas, devido às
características locais do
gerenciamento e da cultura
organizacional ainda em fase
embrionária; contudo, há que se
ressaltar que isso representou,
para a organização e para os
trabalhadores, um grande
avanço na qualidade das
relações entre capital e trabalho.
Foi nessa fase que a área de
RH passou a operacionalizar
serviços como os de
treinamento, recrutamento e
seleção, cargos e salários,
higiene e segurança do
trabalho, benefícios e outros.

Como observado nos trechos acima fica nítido que a fase tecnicista foi um marco para a Administração de Recursos Humanos e nessa época houve um grande avanço das relações trabalhistas nas empresas. Vale ressaltar que assim como na fase legal, a fase tecnicista teve uma grande influência governamental, que dessa vez foi decorrente do governo de Juscelino Kubitschek, em conjunto com a abertura do mercado industrial nacional para as empresas multinacionais do setor automobilístico.

Posteriormente, na Administração de Recursos Humanos, surgiu uma nova fase, denominada administrativa, que se estendeu de 1965 a 1985. Tal época foi marcada por uma revolução nas relações sindicais e por revoluções tecnológicas e de gestão. 
Essa fase é abordada por Marras (2000, p. 26-27) no trecho que se segue:

A fase administrativa criou um marco histórico nas relações entre capital e trabalho, na medida em que é berço de uma verdadeira revolução que, movida pelas bases trabalhadoras, implementou 0 movimento sindical denominado 'novo sindicalismo'. Nessa fase, registrou-se nova mudança significativa - na denominação e na responsabilidade do até aqui gerente de relações industriais: - cargo passou a se chamar gerente de recursos humanos. Pretendia-se com essa mudança transferir a ênfase em procedimentos burocráticos e puramente operacionais para as responsabilidades de ordem mais humanísticas, voltadas para os indivíduos e suas relações (com os sindicatos, a sociedade etc.)

Outros aspectos importantes sobre a fase administrativa também são abordados por Fidelis e Banov (2006, p. 23) a seguir:

Aceleram-se as mudanças tecnológicas alterando a forma de gerencias pessoas. Tecnologia de produção exige habilidades específicas. Nos escritórios, muitas funções passam a ser desenvolvidas por máquinas, com maior eficiência e economia. O microcomputador começa a fazer parte da vida do executivo e aparecer nas fábricas.

Surgem novas teorias e técnicas gerenciais: gestão participativa, planejamento estratégico, controle total de qualidade, entre outras, que vão refletir na maneira de gerenciar pessoas.

Logo, verifica-se que a fase administrativa da Gestão de Pessoas foi um marco evolutivo da área nas organizações, pois a Administração de Recursos Humanos teve que se adaptar às mudanças externas e internas e evoluir juntamente com o mundo ao seu redor.
Após a fase administrativa, surge então a fase conhecida como fase estratégica. Tal fase tem seu surgimento em 1985 e perdura até os dias atuais.

A fase estratégica é descrita por Marras (2000, p. 27) no trecho que se segue:

Foi, assim, nessa fase que se registraram as primeiras preocupações de longo prazo, por parte do board das empresas, com os seus trabalhadores. Inicio-se nova alavancagem operacional do cargo de $\mathrm{GRH}$, que, de posição gerencial, de terceiro escalão, em nível ainda tático, passou a ser reconhecido como diretoria, em nível estratégico nas organizações.

Um cenário importante para o desenvolvimento da fase estratégica da Administração de Recursos Humanos é o que ocorre no início da década de 1990, como descrevem Fidelis e Banov (2006, p. 23) no trecho a seguir:

$\mathrm{Na}$ década de 1990, com o governo Collor, os níveis de empregos e salários baixaram sensivelmente. Elevou-se 0 número de falências $e$ concordatas. Para sobreviver à crise, as empresas utilizaram como estratégia enxugar seus organogramas, diminuir a quantidade de nível hierárquico e atribuir algumas de suas funções a terceiros.

Novamente, vemos o cenário político atrelado ao desenvolvimento da Administração de Recursos Humanos. Dessa vez, é o governo Collor que leva as organizações a repensarem seus organogramas e suas ferramentas de gestão administrativa.

Vale ressaltar que é a partir da fase estratégica da Administração de Recursos Humanos que essa área da empresa passa a ser vista de forma muito próxima a encontrada hoje nas organizações. É a partir dessa época que a Gestão de Pessoas passa a fazer parte do 
pensamento estratégico das organizações. Entretanto, vale dizer que não são todas as empresas que têm tal visão estratégica da área de Administração de Recursos Humanos. Muitas devem estar ainda em fases dos primórdios da Gestão de Pessoas. Entretanto, muitas empresas têm sim realizado uma Gestão de Pessoas atrelada à gestão estratégica da organização, o que mostra o quanto a Gestão de Pessoas cresceu e se desenvolveu durante sua trajetória dentro das corporações.

\section{A IMPORTÂNCIA DA ADMINISTRAÇÃO DE RECURSOS HUMANOS NA GESTÃO ESTRATÉGICA DAS ORGANIZAÇÕES}

Como visto, a Administração de Recursos Humanos evolui muito no decorrer de sua história. Passou de uma área estritamente funcional dentro das organizações e tornou-se um setor que está atrelado, inclusive, aos rumos estratégicos da organização.

No trecho a seguir, Becker, Huselid e Ulrich (2001, p.17) discorrem sobre os primórdios do papel desempenhado pela Administração de Recursos Humanos nas empresas e sua evolução:

As últimas $\begin{array}{r}\text { décadas } \\ \text { testemunharam mudanças }\end{array}$ profundas no papel de RH.
Tradicionalmente, os gerentes
viam a função de recursos
humanos como basicamente
administrativa e profissional. O
pessoal de RH se concentrava
no gerenciamento de benefícios
e de atividades rotineiras, como
folha de pagamento e outras
funções operacionais, e não se
considerava participante da
estratégia geral da empresa.

Porém, hoje a Administração de Recursos Humanos não está restrita apenas à funções operacionais ou táticas. O setor de Gestão de Pessoas tem evoluído e adentrado ao setor estratégico das empresas. Isso porque se os objetivos estratégicos da corporação não estiverem alinhados com a área de Gestão de Pessoas, muito provavelmente tais objetivos estratégicos serão inócuos, já que são as pessoas as responsáveis pela execução do planejamento elaborado pela empresa. No trecho a seguir, Tachizawa, Ferreira e Fortuna (2001, p.126-127) discorrem sobre tal importância das pessoas na organização:

Cada vez mais as organizações percebem que de nada valerão os seus esforços voltados para o mercado e as suas estratégias para ocupar espaços e obter bons resultados se não considerarem que tudo depende da boa execução dos processos que compõem a sua cadeia produtiva, e que a realização desses processos está diretamente ligada à boa gestão das pessoas da organização, pois são elas que, utilizando-se das facilidades que lhes são oferecidas, realizam 0 grande trabalho da produção, atuando diretamente ou indiretamente nos níveis, estratégico, tático e operacional.

Daí a importância de a organização estabelecer um relacionamento adequado com os seus colaboradores, em bases sólidas que só podem ser conseguidas com valores positivos, com políticas e diretrizes compatíveis com a realidade de mercado, com práticas de relações trabalhistas justas e bem aceitas e com um ambiente de trabalho seguro e agradável.

Além dos fatores citados acima, uma Administração de Recursos Humanos eficiente e eficaz pode caracterizar um importante diferencial competitivo para a organização, como afirmam Becker, Huselid e Ulrich (2001, p. 19) no trecho que se segue:

Aprender a atuar como parceiros estratégicos não é apenas um meio para que os profissionais de $\mathrm{RH}$ justifiquem sua existência ou defendam suas funções. Também tem implicações para sua própria 
sobrevivência e para a sobrevivência da empresa como um todo. Se a função $\mathrm{RH}$ for incapaz de demonstrar que agrega valor, ela corre o risco de ser terceirizada. Só por si, isso não é necessariamente ruim; a terceirização de funções ineficientes é capaz de efetivamente melhorar 0 resultado final da empresa. Contudo, também pode significar o desperdício de potenciais imprescindíveis. Com a preocupação correta e boas ferramentas de mensuração, a arquitetura de $\mathrm{RH}$ pode significar a diferença entre uma empresa que apenas acompanha a concorrência e outra que dispara na dianteira.

Fica nítido que a área de Gestão de Pessoas de uma empresa pode contribuir muito para o crescimento e desenvolvimento da organização, fazendo a gestão adequada do capital humano da empresa e alinhando suas atividades com os objetivos estratégicos da corporação, a fim de maximizar resultados para a empresa através do desenvolvimento de suas atividades.

\section{O PAPEL DESEMPENHADO PELA ADMINISTRAÇÃO DE RECURSOS HUMANOS NA REALIDADE ESTRATÉGICA DAS ORGANIZAÇÕES}

A Administração de Recursos Humanos, junto com outras áreas da empresa, deve estar presente na realidade estratégica das organizações, a fim de contribuir para o crescimento e desenvolvimento da organização.

No trecho abaixo, Barbulho (2001, p. 20) discorre sobre tal importância da área de Gestão de Pessoas nas empresas:

Nas grandes empresas e muito mais nas multinacionais existe um plano estratégico (específico para cada uma delas) que tem a visão de ver a empresa no futuro, e por meio de planejamento delineia-se o que deverá ser feito, quais meios adotar para atingi-los e o acompanhamento para as metas, corrigindo os possíveis desvios. É uma das formas encontradas para que a empresa possa crescer una e coesa num mundo globalizado, aproveitando as oportunidades e atingindo seus objetivos. E a área de Recursos Humanos tem de estar envolvida e participando ativamente do processo.

Logo, a Administração de Recursos Humanos precisa estar atrelada ao plano estratégico da organização e tanto um quanto o outro devem caminhar em um mesmo sentido, a fim de alcançarem juntos os melhores resultados possíveis.

Através da Administração de Recursos Humanos, a cultura organizacional pode ser construída de forma que haja a participação efetiva dos colaboradores da organização no processo de construção das estratégias empresariais, já que estes são os que estão lidando com as dificuldades e oportunidades empresariais no dia-a-dia e, portanto, detém um conhecimento muito valioso de quais podem ser as ameaças e oportunidades, pontos fortes e pontos fracos da empresa. Nessa linha de raciocínio Lima e Teixeira (2000, p. 29) afirmam que:

Acreditamos que as empresas podem construir uma cultura organizacional em que as pessoas pensem e ajam estrategicamente, se projetarem e desenvolverem processos contínuos, nos quais as pessoas, em todos os níveis decisórios, em todas as funções, possam falar sinceramente sobre 0 que realmente lhes importa, além de serem escutadas pela alta direção e umas pelas outras.

Esse espírito colaborativo e construtivo tem um potencial muito grande e pode ser amplamente aproveitado na construção de 
estratégias empresariais eficientes e eficazes, aliadas também a uma Administração de Recursos Humanos que possibilite a exploração desse potencial proveniente das pessoas da organização.

Cabe a Administração de Recursos Humanos criar condições para que o capital humano da empresa possa ser explorado de forma a possibilitar a agregação de valor das pessoas aos processos, produtos e serviços prestados e disponibilizados pelas empresas. $\mathrm{Ou}$ seja, a área de Gestão de Pessoas deve possibilitar que as pessoas agreguem valor à companhia. Isto pode ser possibilitado através do trabalho árduo da área de Administração de Recursos Humanos em atrair, desenvolver e reter profissionais qualificados e que possam gerar vantagens competitivas para a empresa através do desempenho de suas atividades e substancialmente pelas ideias e pensamentos estratégicos dos colaboradores que posteriormente possam ser implantados na organização como um todo.

A Administração de Recursos Humanos deve colocar as pessoas certas nos lugares certos e incentivar os colaboradores a pensar e inovar, dar asas a imaginação, criar novas formas para resolver os problemas e desenvolver 0 pensamento estratégico em cada colaborador da instituição, para que isso não fique restrito e a cargo de um setor específico. Segundo Davenport (2001, p. 74) "num mundo competitivo, o que você preferiria? Um departamento de planejamento estratégico buscando liderança no mercado? Ou todos os funcionários pensando em alternativas para levar a empresa ao topo do seu segmento?".

Respondendo a indagação do autor acima, é líquido e certo que é mais vantajoso para a empresa ter todo o seu corpo de funcionários pensando de forma estratégica, do que focar as estratégias da empresa em um grupo restrito e que pode ficar sobrecarregado com tal responsabilidade. Diluindo-se os esforços, é claro que a responsabilidade estratégica ficará mais suave para os colaboradores e ainda assim poderão ser alcançados resultados mais expressivos ainda do que se só um departamento estivesse a cargo das estratégias da organização, porque com a empresa toda pensando de forma estratégica todos poderão contribuir com a sua parcela para a construção de estratégias eficientes e eficazes para a empresa, o que fará com que 0 pouco e simples individual se transforme no muito e elaborado coletivo.

Logo, o papel desempenhado pela Administração de Recursos Humanos na realidade estratégica das organizações é extremamente importante. Proporcionar condições aos colaboradores para estes pensarem e agirem de forma estratégica é algo excepcional e que certamente trará inúmeros resultados positivos para a organização.

\section{MENSURAÇ̃̃O E RESULTADOS DECORRENTES DA ADMINISTRAÇÃO ESTRATÉGICA DE RECURSOS HUMANOS}

A empresa, ao optar por gerir estrategicamente seus recursos humanos, o faz com o objetivo de gerar resultados positivos e agregar valor a empresa, seus processos, produtos e serviços.

O estreito envolvimento do profissional com o seu trabalho permite ao colaborador inovar e desenvolver soluções para os problemas corporativos que possam existir, além de permitir que as pessoas ousem no seu trabalho, com visão estratégica de mercado e gerem, dessa forma, um diferencial competitivo dentro da organização.

\section{A Administração Estratégica de Recursos} Humanos também pode, e deve, gerar resultados efetivamente financeiros para a empresa. Pode, pois é eficiente e eficaz o bastante para ser capaz 
de agregar valores intangíveis e também tangíveis à organização. E deve, pois em uma sociedade capitalista o objetivo de uma empresa é gerar lucro, e a área de Gestão de Pessoas deve contribuir, através do desempenho de suas atividades, para que a empresa possa ter uma maior rentabilidade.

Os retornos financeiros decorrentes da Administração de Recursos Humanos são abordados a seguir por Orlickas (1998, p. 16), onde a autora afirma que:

O desafio de transformar a área de Recursos Humanos de um centro de despesas para um centro de lucro consiste em compreender que 0 investimento em pessoas, seja ele treinamento, remuneração e produtos de $\mathrm{RH}$ diferenciados, se bem gerenciado, poderá se tornar também investimento no business e não única e exclusivamente em pessoas. $\mathrm{E}$ logicamente gerará ótimos retornos para a empresa.

Logo, a Administração de Recursos Humanos é capaz de agregar valor à empresa e pode também, além de investir em pessoas, estar investindo no negócio como um todo.

É interessante observar que por muito tempo, a área de Gestão de Pessoas foi realmente tratada apenas como um centro de despesas administrativas nas organizações como um todo. Mas um diferencial competitivo se dá quando uma empresa consegue transformar essas despesas administrativas em investimentos no seu próprio negócio, para posteriormente gozar dessa aplicação em capital humano dos seus recursos.

Ainda com relação a possibilidade de se obter vantagem competitiva por meio da Gestão de Pessoas, Bohlander, Snell e Sherman (2003, p. 2) em sua obra afirmam que "embora as pessoas sempre tenham sido fundamentais no ambiente empresarial, hoje elas desempenham um papel ainda mais central para a obtenção da vantagem competitiva de uma empresa". Logo, se as pessoas são capazes de possibilitar vantagem competitiva a empresa, a Administração de Recursos Humanos incumbida de gerir tais colaboradores tem um papel muito importante para que a instituição possa se diferenciar e estar em vantagem ante aos seus concorrentes.

$$
\text { Ora, é claro que os resultados obtidos por }
$$

meio da Administração de Recursos Humanos são fundamentalmente importantes para a continuidade dessa atividade na organização e também para delinear seus rumos, pois se tal setor não está agregando valor para a organização, tal área deve ser repensada e suas atividades redesenhadas, a fim de que sejam alcançados resultados positivos para a empresa como um todo. Mas além dos resultados, é importante mensurar se a área de Gestão de Pessoas está desempenhando suas atividades de forma adequada. Tal importância é abordada por Chiavenato (2004, p.490) no trecho que se segue:

Desenhar e implementar um bom sistema integrado de Gestão de Pessoas - capaz de integrar todos os processos de agregar, aplicar, recompensar, desenvolver, manter e monitorar pessoas na organização - é, sem dúvida, um desafio bastante complexo. Mas tornar esse sistema equilibrado, coerente, eficiente e eficaz é outro bem diferente. Como garantir que todos os processos funcionem bem e de maneira integrada e sistêmica? A solução é avaliá-los, monitorálos e auditá-los continuamente. Por essa razão, o planejamento do sistema deve se basear em objetivos sólidos e concretos e que possam servir como indicadores ou padrões de um balizamento para a avaliação dos resultados. Esses objetivos servirão como critérios para se medir e avaliar se o sistema apresenta eficiência e eficácia em todos os seus processos. 
Percebe-se então que a aplicação de um sistema de Gestão de Pessoas deve estar acompanhado de ferramentas que permitam sua mensuração e posterior análise dos resultados obtidos. Isso ocorre pois não adianta nada implementar uma ferramenta de gestão na empresa e não acompanhar e avaliar se os resultados obtidos estão sendo satisfatórios ou não diante do que fora anteriormente estabelecido.

Na Administração de Recursos Humanos, por lidarmos com ativos intangíveis, muitas vezes a mensuração dos resultados obtidos pode ser de difícil visualização, devido à subjetividade muitas vezes encontrada nos fatores analisados. Diante disso Becker, Huselid e Ulrich (2001, p. 16-17) discorrem dizendo:

Assim, o problema de $\mathrm{RH}-0$ fato de seu impacto sobre a estratégia da empresa ser de difícil visualização - é a própria qualidade que também o converte em principal fonte de potencial competitivo sustentável. Contudo, para realizar este potencial, os gerentes de recursos humanos devem compreender a estratégia da empresa; ou seja, seus planos para desenvolver e sustentar uma posição vantajosa no mercado. Em seguida, precisam captar as implicações da estratégia em termos de RH. Em síntese, devem evoluir de uma perspectiva "de baixo para cima" (enfatizando a conformidade e as funções de pessoal tradicionais), para uma perspectiva "de cima para baixo" (enfatizando a implementação da estratégia). Finalmente, necessitam de sistemas de avaliação inovadores que thes permitam demonstrar sua influência sobre os indicadores que de fato importam para os CEOs, principalmente a rentabilidade da empresa e o valor para os acionistas.
Cabe aos gestores de Administração de Recursos Humanos inovarem na hora de buscarem sistemas de avaliação do trabalho desempenhado pela área de Gestão de Pessoas, que mensurem os resultados obtidos pelo desempenho das atividades dessa área da empresa. Tais sistemas de avaliação devem ter como objetivo a mensuração concreta do que realmente está sendo agregado à empresa por intermédio da área de Administração de Recursos Humanos, para que fique nítida a importância dessa área dentro da organização e os resultados decorrentes de seus esforços e atribuições.

\section{CONSIDERAÇÕES FINAIS}

É fato que a Administração de Recursos Humanos traz resultados para a organização como um todo. Seja nos processos, nas ideias obtidas, na inovação dos produtos ou serviços, ou ainda em outras áreas.

Os resultados podem ser os efetivamente financeiros, ou não, como por exemplo, o envolvimento maior dos colaboradores com a organização, que gera um maior engajamento por parte das pessoas que trabalham na empresa. $O$ fato é que os resultados obtidos geram diferencial competitivo para a companhia.

O motivo de se investir nas pessoas é que as empresas são constituídas por elas, ou seja, independentemente do maquinário que a organização possua, da sua frota, da tecnologia patenteada ou da marca registrada, são as pessoas que dão vida a organização e que fazem as coisas efetivamente acontecerem.

E são essas pessoas, os colaboradores, que podem, e, diga-se de passagem, devem contribuir também para os rumos estratégicos da organização. Por exemplo, ninguém melhor do que um trabalhador do chão de fábrica do setor de produção para saber quais são os problemas ali existentes e quais as estratégias possíveis para solucionar tais problemas e além disso 
aperfeiçoar ainda mais as atividades desempenhadas.

O que se afirma aqui é que todos os colaboradores da organização, dentro de suas capacidades, podem contribuir para a construção do futuro estratégico da organização. A estratégia ou as estratégias da empresa podem ser muito mais enriquecidas se todos da organização contribuírem para sua construção do que se isso ficasse a cargo apenas de um restrito grupo de pessoas.

A Administração de Recursos Humanos está evoluindo cada vez mais. Ela saiu daquela área estritamente burocrática e operacional do passado para uma área estratégica dentro das companhias.

Um fato importante é que os investimentos realizados em Gestão de Pessoas convergem para a própria empresa. Ora, se tais investimentos são realizados nas pessoas, e são elas que compõem a organização, logo tais investimentos acabam por ser aplicados no próprio negócio.

Resultados financeiros e engajamento dos colaboradores no desenvolvimento de suas atividades podem ser esperados como consequências da Administração de Recursos Humanos.

Tal área deve estar também atrelada aos rumos estratégicos da organização para que os esforços e investimentos possam convergir nos melhores resultados possíveis, fazendo com que a empresa alcance um diferencial competitivo, que permita a empresa ser um bom local de trabalho para os colaboradores, além de eficiente e eficaz no desempenho de suas atividades.

\section{REFERÊNCIAS}

BARBULHO, E. Recursos humanos: tornando sua empresa mais competitiva: negócio, trabalho, ser humano. São Paulo: Madras Business, 2001.
BARROS, A. J S; LEHFELD, N. A de $S$. Fundamentos de metodologia científica. 3.ed. São Paulo: Pearson Prentice Hall, 2007.

BECKER, B. E.; HUSELID, M. A.; ULRICH, D. Gestão estratégica de pessoas com "scorecard": interligando pessoas, estratégia e performance. 12. ed. Rio de Janeiro: Elsevier, Campus, 2001.

BOHLANDER, G.; SNELL, S.; SHERMAN, A. B.. Administração de recursos humanos. São Paulo: Pioneira, 2003.

CERVO, A. L.; BERVIAN, P. A.. Metodologia científica: para uso dos estudantes universitários. 3. ed. São Paulo: McGraw-Hill, 1983.

CHIAVENATO, I. Gestão de pessoas: o novo papel dos recursos humanos nas organizações. 2. ed., rev. e atual. Rio de Janeiro: Campus, Elsevier, 2004.

CRUZ, C.; RIBEIRO, U. Metodologia científica: teoria e prática. Rio de Janeiro: Axcel Books, 2003.

DAVENPORT, T. O. Capital humano: o que é e por que as pessoas investem nele. São Paulo: Nobel, 2001.

FIDELIS, G. J.; BANOV, M. R. Gestão de recursos humanos: tradicional e estratégica. 1. ed. São Paulo: Érica, 2006.

LIMA, F. O.; TEIXEIRA, P. C. Direcionamento estratégico e gestão de pessoas nas organizações. São Paulo: Atlas, 2000.

MARRAS, J. P.. Administração de recursos humanos: do operacional ao estratégico. 3. ed. São Paulo: Futura, 2000.

ORLICKAS, E. Consultoria interna de recursos humanos: conceitos, casos e estratégias. São Paulo: Makron Books, 1998.

SOVIENSKI,, F.; STIGAR, R. Recursos Humanos x Gestão de Pessoas. Gestão: Revista Científica de Administração e Sistemas de Informação. Curitiba, v. 10, n. 10, p. 51-61, jan./jun. 2008.

TACHIZAWA, T.; FERREIRA, V. C. P.; FORTUNA, A. A. M.. Gestão com pessoas: uma abordagem aplicada às estratégias de negócios. 2. ed. Rio de Janeiro: Fundação Getúlio Vargas, 2001. 